\title{
Fatigue in Survivors of Autoimmune Encephalitis
}

Luisa A. Diaz-Arias, MD, * Anusha Kierty Yeshokumar, MD, * Brittany Glassberg, MD, James F. Sumowski, PhD, Ava Easton, PhD, John C. Probasco, MD, and Arun Venkatesan, MD, PhD

Neurol Neuroimmunol Neuroinflamm 2021;8:e1064. doi:10.1212/NXI.0000000000001064

\section{Abstract}

\section{Background and Objectives}

To evaluate the impact of fatigue after autoimmune encephalitis, determine associations with patients' characteristics, and identify factors that contribute to its development.

\section{Methods}

In a first cohort recruited via several encephalitis support organizations, self-reported questionnaires were used to evaluate fatigue, depression, and sleep quality in adults after autoimmune encephalitis. In a second cohort where more in-depth clinical characterization could be performed, adults with encephalitis from 2 tertiary hospitals were evaluated using the same questionnaires. Patients' characteristics were retrospectively captured.

\section{Results}

In the first cohort (mean [SD] age; 43 [16] years, 220 [65\%] female), 220 of 338 participants (65\%) reported fatigue, 175 of 307 (57\%) depression, and 211 of 285 (74\%) poor sleep quality. In the second cohort (48 [19] years; $43[50 \%]$ women), 42 of 69 participants (61\%) reported fatigue, whereas 23 of 68 (34\%) reported depression and 44 of 66 (67\%) poor sleep quality, despite more than $80 \%$ having "good" modified Rankin scale (mRS) scores (0-2). Individuals with anti-NMDA receptor encephalitis reported lower fatigue scores than those with other autoimmune encephalitis types. In a multivariate analysis examining factors at discharge that might predict fatigue scores, only anti-NMDA receptor encephalitis was a (negative) predictor of fatigue and remained so when potential confounders were included.

\section{Discussion}

The impact of fatigue after autoimmune encephalitis is prominent and not fully accounted for by depression or sleep quality, nor adequately captured by mRS scores for disability. Fatigue is pervasive across autoimmune encephalitis, although lower scores are reported in anti-NMDA receptor encephalitis. Fatigue should be screened routinely, considered as an outcome measure in clinical trials, and further studied from a mechanistic standpoint.
Correspondence

Dr. Venkatesan

avenkat2@jhmi.edu 


\section{Glossary}

$\mathrm{AE}=$ adverse event; BDI-Fast Screen $=$ Beck Depression Inventory-Fast Screen; CASE $=$ clinical assessment scale in AE; ICU = intensive care unit; ISMMS = Icahn School of Medicine at Mount Sinai; mRS = modified Rankin scale; MFIS = Modified Fatigue Impact Scale; PPHS = Program for the Protection of Human Subjects; PSQI = Pittsburgh Sleep Quality Index; SREAT $=$ steroid-responsive encephalopathy associated with autoimmune thyroiditis.

Encephalitis is a potentially life-threatening neurologic disorder. Infections have historically been the most frequently recognized cause, although there has been a growing appreciation of autoimmune etiologies. ${ }^{1,2} \mathrm{~A}$ large proportion of survivors are left with physical, cognitive, and behavioral dysfunction that may affect the quality of life. ${ }^{1,3}$ In a United Kingdom cohort, $25 \%$ reported psychiatric sequelae, $10 \%$ headaches, $7 \%$ epilepsy, and $5 \%$ cognitive problems. ${ }^{4}$ More recently, a wide range of neuropsychological impairments, including tiredness, depression, and anxiety, were reported after encephalitis. ${ }^{5}$ In a cohort of 77 patients evaluated after an adverse event $(\mathrm{AE}), 86 \%$ had at least 1 neurobehavioral symptom and half were unable to return to work. ${ }^{6}$

To tailor strategies to improve the quality of life and incorporate meaningful patient-reported outcome measures in clinical trials, a more nuanced understanding of the consequences of $\mathrm{AE}$ is needed. Although there have been attempts to more precisely define consequences in specific $\mathrm{AE}$ subgroups, ${ }^{7-12}$ such approaches do not readily permit comparison among $\mathrm{AE}$ forms. In addition, limited attention has been paid to fatigue, which in the context of CNS disorders refers to enhanced perception of effort and limited endurance of sustained activities. ${ }^{13}$ Fatigue substantially limits the quality of life in other neurologic illnesses and is potentially treatable. ${ }^{6,14}$ We hypothesized that fatigue was prevalent and affected the quality of life after an $\mathrm{AE}$ and that distinct clinical characteristics might predict patients at most risk. To test our hypotheses, we characterized fatigue in 2 large cohorts of patients with $\mathrm{AE}$ and determined associations with clinical features.

\section{Methods}

\section{Participants and Study Design}

\section{Cohort 1}

We developed a cross-sectional study using a network of several encephalitis patient support organizations (Encephalitis Society, Autoimmune Encephalitis Alliance, International Autoimmune Encephalitis Society, and Encephalitis 411) to recruit patients between 18 and 84 years of age with a selfreported diagnosis of encephalitis. Patients received questionnaires to evaluate fatigue, depression, and sleep quality from June 2019 to October 2019. The questionnaires were sent electronically using the secure web application REDCap. Demographics, encephalitis etiology, date at symptom onset, date at diagnosis, and date at treatment initiation were collected.

\section{Cohort 2}

To validate and expand on the findings from the initial cohort, we developed a retrospective cross-sectional study at 2 tertiary hospitals in the United States in which extensive clinical characterization was performed, thus enabling us to study potential associations between clinical features and fatigue. The Encephalitis Center at Johns Hopkins Hospital, Baltimore, MD, is a worldwide referral site for patients with encephalitis. A.K.Y. is an autoimmune neurologist who cares for patients with encephalitis at the Icahn School of Medicine at Mount Sinai in New York City. Consecutive adult patients identified through an encephalitis registry and in outpatient clinics whom we diagnosed with AE per consensus criteria ${ }^{15}$ were approached for study enrollment between October 2019 and March 2020. Patients were invited to participate if at least 6 months had elapsed since the onset of acute symptoms of AE without clinical relapse. Patients filled out the survey instruments in person, via phone, or email, and all data were collected in a REDCap database.

Demographics and clinical data were captured by medical record review: encephalitis etiology, encephalitis type, time from symptom onset to diagnosis, time from diagnosis to treatment initiation, need for hospitalization, need for intensive care unit (ICU), and MRI brain abnormalities (associated encephalitis abnormalities were defined as neuroimaging findings suggestive of $\mathrm{AE},{ }^{16}$ whereas nonassociated encephalitis abnormalities were those findings suggestive of other underlying pathologies [e.g., chronic microvascular ischemic changes]), CSF (white cell count $>5$ leukocytes $/ \mathrm{mm}^{3}$ and protein $\geq 50 \mathrm{mg} / \mathrm{dL}$ ) abnormalities, length of stay in the hospital and ICU, modified Rankin scale (mRS) at discharge, and for AE participants, need for second-line immunotherapy (defined as rituximab and/or cyclophosphamide). Several additional variables were collected at the time of study enrollment: time from symptom onset to study enrollment, mRS score at study enrollment, and clinical assessment scale in AE (CASE) score (in participants with $\mathrm{AE}$ ). An mRS of $0-2$ was defined as "good outcome" and 3-6 as "poor outcome." ${ }^{17}$ CASE is a scale that rates the severity of $\mathrm{AE}$ and includes seizure status, degree of memory dysfunction, the presence of psychiatric symptoms, the level of consciousness, language problems, the degree of dyskinesia or dystonia, gait instability and ataxia, brainstem dysfunction, and weakness. ${ }^{18}$

\section{Standard Protocol Approvals, Registrations, and Patient Consents}

The cross-sectional study was approved by the Program for the Protection of Human Subjects (PPHS) at the Icahn School of 
Figure 1 Fatigue, Depression, and Sleep Quality in Cohort 1 (A) and Cohort 2 (B) as Assessed by the MFIS, BDI-Fast Screen, and PSQI
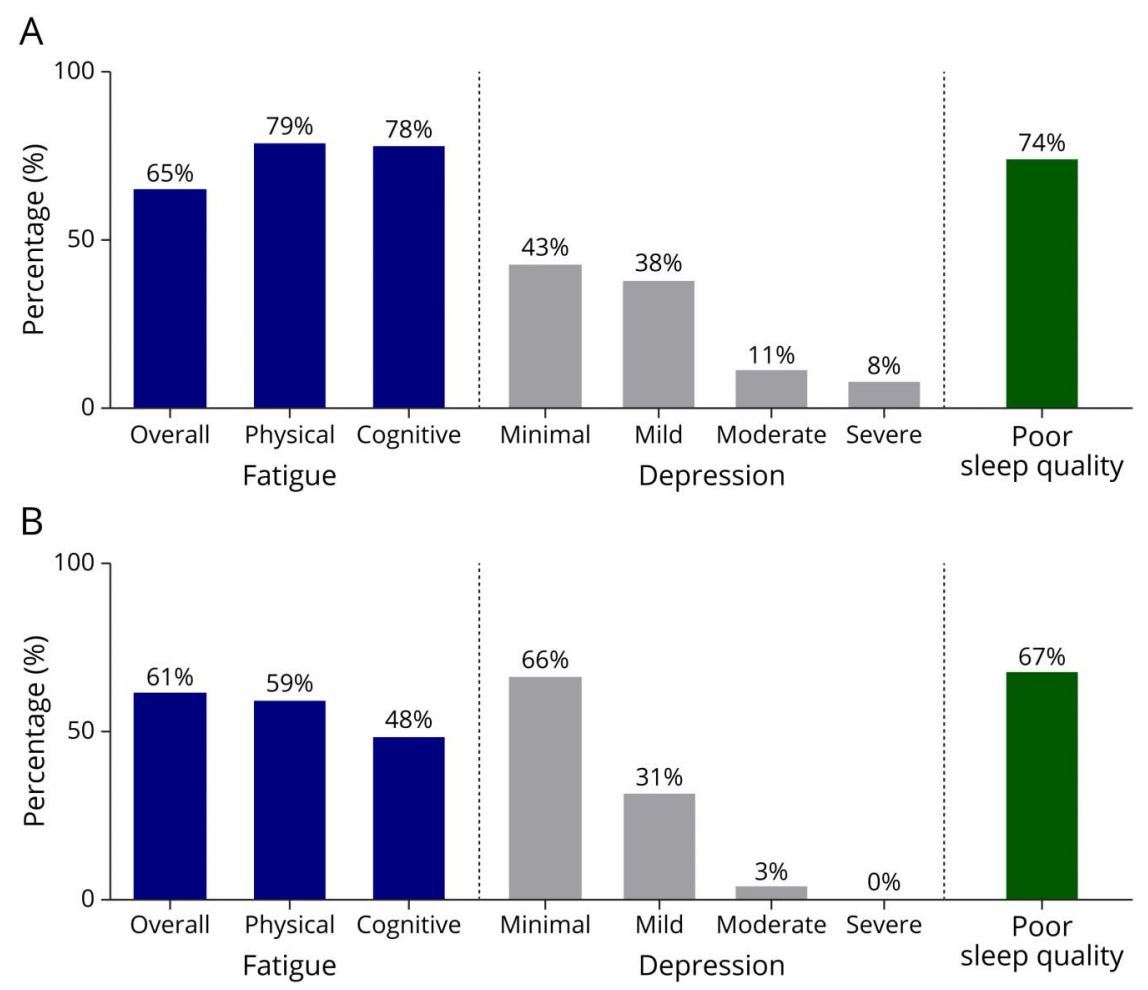

BDI-Fast Screen $=$ Beck Depression Inventory-Fast Screen; MFIS = Modified Fatigue Impact Scale; PSQI = Pittsburgh Sleep Quality Index.

Medicine at Mount Sinai (ISSMS). The Johns Hopkins Medicine Institutional Review Boards and the PPHS at ISSMS approved the study protocol for cohort 2 at both tertiary hospitals. Patients provided informed consent for access to their clinical records and completion of questionnaires.

\section{Fatigue, Depression, and Sleep Quality Assessment}

In addition to the data collected from medical record review, participants were asked to complete the Modified Fatigue Impact Scale (MFIS), ${ }^{19-21}$ along with the Beck Depression Inventory Fast Screen (BDI-Fast Screen) ${ }^{22}$ and Pittsburgh Sleep Quality Index (PSQI). ${ }^{23}$

The MFIS is a 21-item modified version of the Fatigue Impact Scale that evaluates the impact of fatigue on the quality of life. ${ }^{19}$ It has an overall score and 3 subscales assessing physical, cognitive, and psychosocial fatigue. This scale has excellent reliability and validity and has been broadly implemented in multiple neurologic disorders. ${ }^{14,24}$ Higher scores denote greater impact of fatigue on the quality of life. The overall fatigue scale ranges from 0 to 84 , and the physical and cognitive subscales range from 0 to 36 and 0 to 40 , respectively. We implemented previously reported cutoff values of 29 for overall fatigue, 14.5 for physical fatigue, and 18.5 for cognitive fatigue. ${ }^{25,26}$ Given the lack of norms for the psychosocial subscale, ${ }^{27}$ we did not include this in our analyses.
The BDI-Fast Screen evaluates depression and severity in adults. $^{22,28}$ It consists of 7 items from the original 21-item BDI-II, with a 4-point scale from zero (symptom absent) to 3 (severe symptoms). The minimum score is 0 , and the maximum is 21 . The cutoff value for depression is 4; a score of 4-8 indicates mild depression, 9-12 moderate depression, and 13-21 severe depression.

The PSQI measures 7 clinically derived sleep-related domains, including subjective sleep quality, sleep latency, sleep duration, habitual sleep efficiency, sleep disturbances, the use of sleeping medications, and daytime dysfunction. ${ }^{23}$ It contains 9 items, 4 of which are open questions, 4 are measured on a 4-point scale from zero (not during the past month) to 3 ( 3 or more times a week), and the last asks the patient to rate sleep quality from zero (very good) to 3 (very bad). Higher scores indicate worse sleep quality, with a score of 5 and above defining poor sleep quality. The questionnaire holds high validity and reliability. ${ }^{29}$

\section{Statistical Analysis}

Descriptive statistics, including frequencies and percentages for categorical data, were used to describe outcomes, demographics, and clinical characteristics of both cohorts. Two sample $t$ test or Pearson correlation coefficient, as appropriate, were used in univariate analyses to test the effects of demographics and clinical characteristics on outcomes (primary outcome measure was the MFIS overall score). Because anti- 
Table 1 Demographics and Clinical Characteristics of Cohort 2

\begin{tabular}{ll}
\hline $\begin{array}{l}\text { Demographic and clinical features at initial } \\
\text { presentation }\end{array}$ & $\mathbf{n}=69$ \\
\hline Sex: female, $\mathbf{n}(\%)$ & $34(49)$ \\
\hline Age, $\mathbf{y}$, mean (SD) & $48(19)$ \\
\hline Ethnicity, $\mathbf{n}(\%)$ & $63(93)$ \\
\hline Non-Hispanic or Latino & $5(7)$ \\
\hline Other & $49(71)$ \\
\hline Race, $\mathbf{n}$ (\%) & $20(29)$ \\
\hline White & $14(20)$ \\
\hline Other & $55(80)$ \\
\hline Encephalitis etiology, $\mathbf{n}(\%)$ & $4(3)$ \\
\hline Anti-NMDA receptor & \\
\hline Other autoimmune & \\
\hline
\end{tabular}

Months from symptom onset to study enrollment, 4 (3) mean (SD)

Months from symptom onset to diagnosis, mean (SD) 0.6 (8)

Months from symptom onset to treatment, mean (SD) 0.6 (8)

Need for hospitalization, $n$ (\%)

\begin{tabular}{ll}
\hline Yes & $60(87)$ \\
\hline No & $9(13)$ \\
\hline ICU admission, $\mathbf{n}(\%)$ & \\
\hline Yes & $12 / 65(18)$ \\
\hline No & $53 / 65(82)$ \\
\hline Length of hospitalization, d, mean (SD, range) & $21.9(20.6,2-84)$ \\
\hline Length of ICU stay, d, mean (SD, range) & $22.4(22.3,2-61)$ \\
\hline
\end{tabular}

CSF WBC, $\mathrm{n}(\%)$

\begin{tabular}{|c|c|}
\hline WBC $>5$ leukocytes $/ \mathrm{mm}^{3}$ & $26 / 66$ (39) \\
\hline WBC $\leq 5$ leukocytes $/ \mathrm{mm}^{3}$ & $40 / 66(61)$ \\
\hline \multicolumn{2}{|l|}{ CSF protein, $\mathbf{n}(\%)$} \\
\hline Protein $\geq 50 \mathrm{mg} / \mathrm{dL}$ & 29/67 (43) \\
\hline Protein $<50 \mathrm{mg} / \mathrm{dL}$ & $38 / 67(57)$ \\
\hline Encephalitis-associated MRI abnormalities, n (\%) & $24(35)$ \\
\hline \multicolumn{2}{|l|}{ mRS at discharge, n (\%) } \\
\hline$\geq 3$ & $49 / 57(86)$ \\
\hline$<2$ & 8/57 (14) \\
\hline
\end{tabular}

Abbreviations: $\mathrm{ICU}=$ intensive care unit; $\mathrm{mRS}=$ modified Rankin scale; $\mathrm{WBC}=$ white blood count.

NMDA receptor encephalitis represents the most common and readily recognized form of $\mathrm{AE}$ and reported outcomes have been more favorable, ${ }^{30}$ we specifically examined the hypothesis that participants with anti-NMDA receptor encephalitis fare better than those with other forms of AE. Differences in demographics, clinical features, and outcomes between anti-NMDA receptor encephalitis and other forms of AE were evaluated with $\chi^{2}$ test and 2-sample $t$ test. To understand which variables predicted overall fatigue in the entire cohort, those associated with outcome in univariate analyses were examined in a multivariate analysis. Colinearity tests were run for all examined variables. Factors that have been shown in previous literature to predict outcomes (sex, age at symptom onset, time from symptom onset to treatment initiation, need for hospitalization, ICU admission, CSF pleocytosis, CSF hyperproteinorachie, encephalitis-associated MRI abnormalities, $\mathrm{mRS}$ at discharge, and encephalitis type), as well as potential confounders measured at the time of study enrollment (depression, sleep quality, age at study enrollment, employment status, time from symptom onset to study enrollment, mRS, the presence of active malignancy, the use of corticosteroids, report of pain, and the use of antidepressants at study enrollment), were added to the model in a stepwise fashion to confirm that noted associations were not mediated by other relevant factors. The fit of the final model was evaluated by the $F$-test for linear regression. Statistical significance was considered if $p<0.05$ without adjustment for multiple testing. The analysis was performed using $\mathrm{R}$ version 3.6.3 (R Foundation for Statistical Computing, St. Louis, $\mathrm{MO}$ ) and IBM SPSS Statistics (SPSS, Inc., Chicago, IL).

\section{Data Availability}

Data not published in this article can be made available for any qualified investigator with maintenance of patient anonymity.

\section{Results}

\section{Cohort 1}

Three hundred thirty-eight participants completed the fatigue survey and were at least 6 months from symptom onset. A total of 307 (91\%) of these 338 completed the depression questionnaire and 285 (84\%) completed the sleep quality survey. Demographics and clinical characteristics are described in supplementary materials (eTable 1, links.lww.com/ $\mathrm{NXI} / \mathrm{A} 558)$. Importantly, no differences were found in demographics or clinical characteristics between those who completed all surveys and those who did not.

Fatigue was commonly reported in this cohort. On the MFIS, $220(65 \%)$ participants reported overall fatigue, 268 (79\%) physical fatigue, and $264(78 \%)$ cognitive fatigue. On the BDI-Fast Screen, 57\% reported depression (175/307), whereas on the PSQI, 74\% (211/285) reported poor sleep quality (Figure 1).

\section{Cohort 2}

\section{Participants}

Sixty-nine participants were included in the analyses (eFigure 1, links.lww.com/NXI/A558). Of these 69, all (100\%) 
Figure 2 Fatigue in Anti-NMDA Receptor Encephalitis vs Other Autoimmune Encephalitis Etiologies

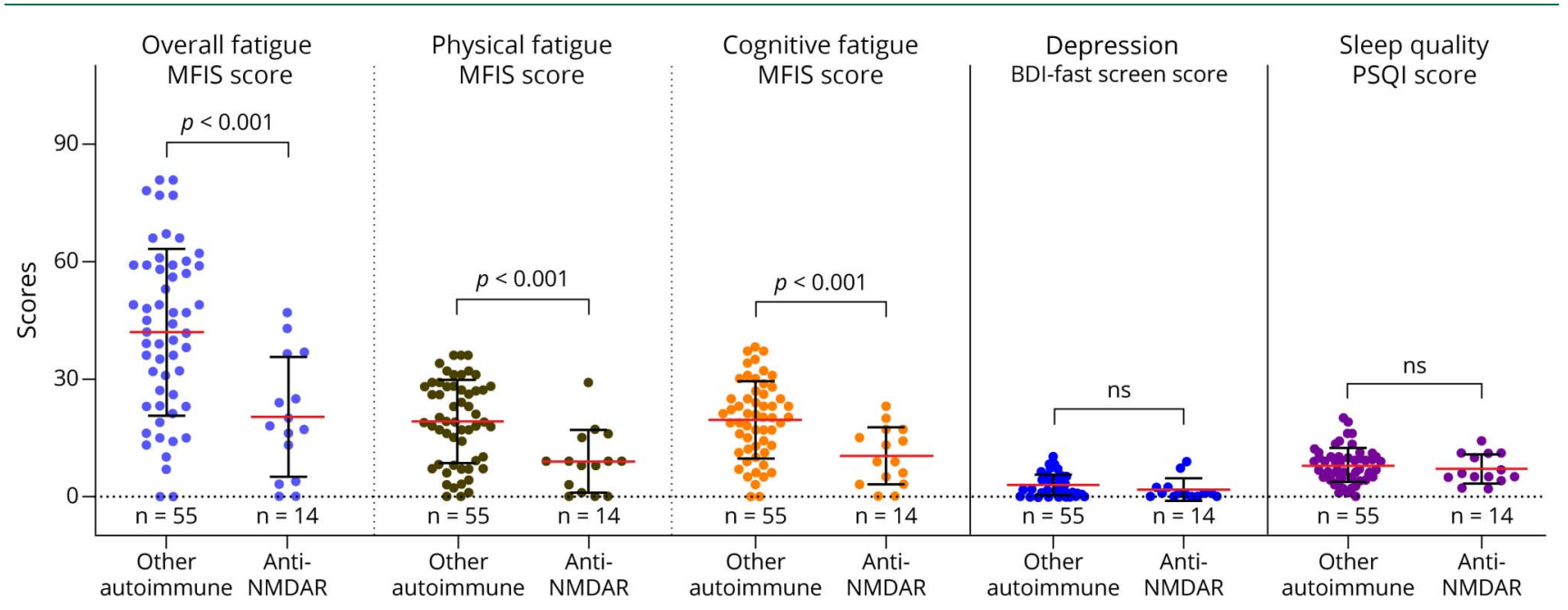

Scatter dot plots of fatigue, depression, and sleep quality. BDI-Fast Screen = Beck Depression Inventory Fast Screen; MFIS = Modified Fatigue Impact Scale; PSQI = Pittsburgh Sleep Quality Index.

completed the fatigue questionnaire, 68 (98.5\%) completed the depression survey, and 66 (95.6\%) completed the sleep quality questionnaire.

\section{Demographics and Clinical Characteristics}

Of the 69 participants who completed the fatigue questionnaire, 34 (49.3\%) participants were women. Forty-nine (71\%) were White or Caucasian and $4(5.8 \%)$ Black or African American. Thirty-eight (55.1\%) were married, and 24 (34.8\%) single. Forty-nine (71\%) were able to work or study and 20 (28.9\%) were unable to work. Thirty (43.5\%) participants had seronegative AE, 14 (20.3\%) anti-NMDA receptor encephalitis, 9 (13\%) steroid-responsive encephalopathy associated with autoimmune thyroiditis (SREAT), 6 (8.6\%) anti-LGI1 encephalitis, and $4(5.8 \%)$ anti-CASPR2 encephalitis. Four (5.8\%) participants had paraneoplastic encephalitis and 2 (2.8\%) had an active malignancy at study enrollment. Importantly, no differences were found in demographics nor in clinical characteristics (including need for ICU admission, CSF pleocytosis, CSF protein, and encephalitis-associated MRI abnormalities) between those who completed all surveys in cohort 2 and those who did not. However, a few clinical features differed between the 2 groups. Participants who completed all surveys had a longer interval between symptom onset and treatment initiation (complete $=223.8$ days, incomplete $=18.3$ days, 95\% CI 97.3-313.6, $p<0.001$ ), prolonged length of hospitalization (complete $=21.9$ days, incomplete $=9.75$ days, 95\% CI 0.99-23.3, $p=0.03$ ), and more frequently received second-line immunotherapy (complete $=34 / 69(50 \%)$, incomplete $=0 / 6(0 \%), 95 \%$ CI $0.4-0.6, p=0.02)$ than those who did not.

In cohort 2, the mean age of participants at symptom onset was 45 years (SD 20, range 14-85 years). Of 60 (87\%) participants who required hospitalization, 12 (17\%) were admitted to the ICU. The mean length of hospitalization was 21.9 days (SD 20.6, 2-84 days), and the mean length of ICU stay was 22.4 days (SD 22.3, 2-61 days). MRI brain and CSF white blood cell count and/or protein were abnormal in 24 (35\%) and 38 (55\%) participants, respectively. Thirty-four (49\%) received second-line immunotherapy, defined as rituximab and/or cyclophosphamide. Forty-nine (71\%) participants had an $\mathrm{mRS} \geq 3$ at discharge (Table 1).

At the time of study enrollment, mean age was 48 years (SD 19 , range 18-89 years). Mean time from symptom onset to study enrollment was 3.7 years (SD 2.8, 0.5 to 15.4 ). Eleven (16\%) had a current $m R S \geq 3$, and $67(97 \%)$ participants had a CASE score $\leq 5$.

\section{Evaluation of Fatigue}

In cohort 2, $42(61 \%)$ of 69 participants reported overall fatigue, 41 (59\%) physical fatigue, and 33 (48\%) cognitive fatigue. Only 23 (34\%) of 68 participants reported depression, and $44(67 \%)$ of 66 participants reported poor sleep quality. Fatigue was more common than depression (95\% CI 0.1-0.4, $p<0.001)$ but not more frequent than poor sleep quality (95\% CI -0.2 to $0.1, p=0.6$ ) (Figure 1 ). Variables hypothesized to be related to overall fatigue were tested in univariate analyses (eTable 2, links.lww.com/NXI/A558). There were no differences in fatigue by demographic factors, the presence of MRI abnormalities, or routine CSF testing.

Time from symptom onset to treatment initiation was positively correlated with the impact of overall $(r=0.2,95 \% \mathrm{CI}$ $0.1-0.5, p=0.01)$ and physical $(r=0.3,95 \%$ CI $0.1-0.5, p=$ $0.01)$ fatigue at study enrollment. No differences were found in overall (95\% CI -22.9 to $13.1, p=0.9$ ), physical fatigue (95\% CI -12.7 to $3.3, p=0.2$ ) nor cognitive fatigue (95\% CI -9.4 to $8.5, p=0.9)$ between participants with $\mathrm{mRS}<3$ vs $\geq 3$ 
Table 2 A Multivariate Analysis of the Predictors of Fatigue

\begin{tabular}{|c|c|c|}
\hline & Standardized $\beta$ & $p$ Value \\
\hline Age at symptom onset & -0.2 & 0.2 \\
\hline Encephalitis type & -0.4 & 0.002 \\
\hline \multicolumn{3}{|l|}{ Anti-NMDA receptor encephalitis } \\
\hline \multicolumn{3}{|l|}{ Others } \\
\hline Time from symptom onset to treatment initiation & 0.2 & 0.1 \\
\hline ICU admission & 0.1 & 0.4 \\
\hline \multicolumn{3}{|l|}{ Yes } \\
\hline \multicolumn{3}{|l|}{ No } \\
\hline CSF white blood count & 0.01 & 0.9 \\
\hline \multicolumn{3}{|l|}{$\leq 4$ cells } \\
\hline \multicolumn{3}{|l|}{$>4$ cells } \\
\hline CSF protein & -0.07 & 0.5 \\
\hline \multicolumn{3}{|l|}{$\leq 50$} \\
\hline \multicolumn{3}{|l|}{$>50$} \\
\hline Nonencephalitis-associated MRI brain abnormalities & 0.09 & 0.4 \\
\hline \multicolumn{3}{|l|}{ Yes } \\
\hline \multicolumn{3}{|l|}{ No } \\
\hline Encephalitis-associated MRI brain abnormalities & -0.09 & 0.4 \\
\hline \multicolumn{3}{|l|}{ Yes } \\
\hline \multicolumn{3}{|l|}{ No } \\
\hline mRS at discharge & 0.2 & 0.1 \\
\hline \multicolumn{3}{|l|}{$\geq 3$} \\
\hline \multicolumn{3}{|l|}{$<2$} \\
\hline$R^{2}$ & 0.15 & NA \\
\hline Adjusted $R^{2}$ & 0.14 & NA \\
\hline
\end{tabular}

Boldface refers to variables where $p$ value is $<0.05$.

Abbreviations: ICU = intensive care unit; $\mathrm{mRS}$ = modified Rankin scale; NA = not available.

at discharge. There were no differences in fatigue, depression, nor sleep quality in those who received second-line immunotherapy vs first-line immunotherapy only.

Reassuringly, time from symptom onset to study enrollment was not correlated with fatigue, suggesting that our findings were not confounded by the interval to enrollment (eFigure 2, links.lww.com/NXI/A558). The impact of physical fatigue was significantly higher in participants with $\mathrm{mRS} \geq 3$ at study enrollment than in those with $\mathrm{mRS}<3$ (95\% CI -15.4 to -1.8 , $p=0.02$ ), but depression and sleep quality scores did not differ by mRS. Fatigue was not different among participants who were using corticosteroids, antidepressants, or who reported pain or had an active malignancy at study enrollment. Fatigue scores did not differ among participants unable to work because of encephalitis sequelae than in those who were able to work or study.

Fatigue was moderately correlated with depression $(r=0.5$, 95\% CI 0.3-0.6, $p<0.001)$ and sleep quality $(r=0.4,95 \% \mathrm{CI}$ $0.2-0.6, p<0.001)$, and depression was also moderately correlated with sleep quality $(r=0.3,95 \%$ CI $0.01-0.5, p<$ 0.001 ).

\section{Anti-NMDA Receptor Encephalitis Compared With Other Forms of Autoimmune Encephalitis}

In cohort 2, individuals with anti-NMDA receptor encephalitis reported significantly lower impact of overall (95\% CI -31.6 to $-10.5, p<0.001)$, physical $(95 \% \mathrm{CI}-15.4$ to -4.5 , $p$ $<0.001)$, and cognitive (95\% CI -13.8 to $-3.8, p=0.001)$ 
fatigue on the quality of life than those with other forms of $\mathrm{AE}$ (Figure 2), whereas depression and sleep quality scores did not differ between these groups.

In interrogating reasons for these differences, it was noted that the 2 groups differed by age and time to diagnosis and treatment. Both at symptom onset and at the time of study enrollment, participants with anti-NMDA receptor encephalitis were younger than those with other types of encephalitis (95\% CI 12.7-29.4, $p<0.001$ ). The time from symptom onset to diagnosis (anti-NMDA receptor encephalitis 35.4 days [SD 35.5] vs others 296.3 days [SD 496], 95\% CI 123.8-392.9, $p<0.001$ ) and to treatment (anti-NMDA receptor encephalitis 36.6 days [SD 31.3]) vs others 289.9 days [SD 491.4], 95\% CI 116.9-380.6, $p<0.001)$ were also lower in anti-NMDA receptor encephalitis participants. Those with anti-NMDA receptor encephalitis were more likely to receive second-line immunotherapy than those with other forms of $\mathrm{AE}(95 \% \mathrm{CI}-0.65$ to -0.06$), p=0.03)$ and less likely to be of White race ( $95 \% \mathrm{CI}-0.04$ to $0.7, p=0.01$ ) (eTable 3, links. lww.com/NXI/A558).

To determine whether the marked difference in time from symptom onset to treatment might account for observed differences in fatigue outcomes, we next restricted analysis to the 51 individuals across all forms of $\mathrm{AE}$ in whom disease was recognized and treated early in their clinical course (defined as duration of symptom onset to treatment less than 60 days). In this subset, rates of fatigue remained substantially lower in anti-NMDA receptor encephalitis patients compared with all other patients with $\mathrm{AE}$ (anti-NMDA receptor encephalitis 20 [16.4] vs others 36.8 [SD 22], 95\% CI 3.7-29.8, $p=0.01$ ).

\section{Other Predictors of Fatigue}

To characterize which demographic and clinical variables from acute illness portend future impact of fatigue on quality of life, the factors from the time of initial presentation that were individually associated with overall fatigue were examined in a multivariate analysis. Variables shown to affect longterm outcomes in the literature were also included (Table 2) ${ }^{17,31}$ Only anti-NMDA receptor encephalitis $(\beta=$ $-0.38,95 \%$ CI -34.01 to $8.1, p=0.002$ ) was a (negative) predictor for fatigue $\left(F(1,60)=10.5, R^{2}=0.15, R_{\text {adjusted }}^{2}=\right.$ $0.14, p=0.002)$. To ensure that this association was not mediated by other relevant factors from the time of study enrollment, we subsequently included employment status, age at study enrollment, time from symptom onset to study enrollment, depression, sleep quality, mRS, the presence of active malignancy, the use of corticosteroids, antidepressants, and pain at study enrollment into a model examining antiNMDA receptor encephalitis and fatigue. In this model, depression $(\beta=0.43,95 \%$ CI $2-5.1, p<0.001)$, mRS at study enrollment $(\beta=0.3$, 95\% CI 6.1-27.7, $p=0.003)$, and sleep quality $(\beta=0.3,95 \%$ CI $0.5-2.5, p=0.003)$ positively predicted fatigue, whereas anti-NMDA receptor encephalitis $(\beta=$ $-0.3,95 \% \mathrm{CI}-24.9$ to $-5.1, p=0.004)$ remained a negative predictor $\left(F(4,61)=15.9, R^{2}=0.51, R_{\text {adjusted }}^{2}=0.48, p<\right.$
0.001). Therefore, the impact of fatigue on the quality of life after encephalitis was not completely accounted for by depression or sleep quality.

\section{Discussion}

In this study, we demonstrate the high impact of fatigue on the quality of life in a broad population of individuals affected by AE. Notably, neither the mRS nor the CASE scale adequately capture fatigue as an outcome because many patients with good mRS or CASE scores at study enrollment reported high levels of fatigue impact. Moreover, mRS scores at hospital discharge did not predict subsequent development of fatigue. Thus, fatigue must be directly ascertained, given its significant impact on the quality of life and the fact that it is a potentially treatable condition.

Previous studies have demonstrated the overlap of fatigue with some psychiatric and sleep disorders. ${ }^{32,33}$ In a cohort of 60 patients with anti-LGI1 encephalitis, fatigue was not only a common and debilitating symptom but also demonstrated a significant correlation with depression and anxiety. ${ }^{34}$ Furthermore, fatigue has also been correlated with depression and sleep abnormalities in MS and Parkinson disease. ${ }^{35,36}$ Although fatigue and depression may share some characteristics, there are also important differences. For example, patients with chronic fatigue syndrome, as opposed to depression, do not usually feel guilty, have low self-esteem, or experience inward attribution of their symptoms. ${ }^{37}$ To mitigate against the potential overlap between depression and fatigue, we assessed depression by the BDI-Fast Screen, which focuses on the affective and cognitive aspects of depression, as compared to the BDI-I or BDI-II which also include a somatic component that may more readily reflect the aspects of fatigue. ${ }^{38}$ We found that fatigue after $\mathrm{AE}$ was indeed correlated with depression and sleep quality, but only partially accounted for by these 2 disorders, suggesting that fatigue is on its own an important sequela.

The underlying pathophysiology of fatigue among neurologic disorders is not well understood. The biological causes of fatigue have perhaps been best explored in the context of MS. Several categories of pathophysiologic mechanisms have been suggested, including structural damage and atrophy in both gray and white matter, maladaptive network recruitment, and immune activation. ${ }^{39}$ The hypothalamus has also received attention as a potential mediator of fatigue in MS. ${ }^{40}$ Regarding network disruption, a number of fMRI studies demonstrate increased activation in both motor and nonmotor regions that are associated with fatigability in motor and cognitive tasks and that may indicate compensatory activity in the setting of an underlying dysfunction. ${ }^{41}$ Notably, to date, there are limited reports of neuroimaging correlates of outcome after encephalitis and none describing the relationship between such correlates and fatigue. ${ }^{42,43}$ We found no relationship between fatigue outcomes and the presence of encephalitis-associated 
abnormalities on clinical MRI imaging. However, prospective studies that include structural and functional imaging measures are needed to better evaluate potential associations.

It is well known that ongoing central and peripheral immunologic processes may drive fatigue in the context of neurologic disease through a variety of mechanisms, including via reduction of mesolimbic pathways responsible for pursuit of rewards. ${ }^{44}$ We found that fatigue was prominent in participants with AE. This was anticipated because autoimmune causes may result in chronic or relapsing neuroinflammation after the acute phase. ${ }^{45}$ The question remains as to whether fatigue is also a prominent complaint in infectious encephalitis, given new evidence of subsequent CNS autoimmune processes in some of these cases. For instance, reports have demonstrated neuroinflammation after herpes simplex encephalitis and other viruses. Furthermore, a recent report notes persistently elevated tumor necrosis factor a levels up to 3 years after West Nile virus encephalitis. ${ }^{46,47}$ If fatigue is found to occur after infectious encephalitis, this suggests that overt or subtle ongoing inflammation could account for its development as well.

Although long-term outcomes after anti-NMDA receptor encephalitis have been described as overall quite favorable, this is an evolving field. Recently, fatigue has been reported in a pediatric cohort. ${ }^{7,48,49}$ Although our anti-NMDA receptor encephalitis patients reported substantial fatigue, the diagnosis of anti-NMDA receptor encephalitis was a negative predictor of fatigue as compared to other etiologies. Depression and sleep quality did not differ between anti-NMDA receptor encephalitis and other AE, suggesting the specificity of our findings. Although the biology underlying anti-NMDA receptor encephalitis may potentially result in a favorable prognosis as compared to other forms of $\mathrm{AE}$, factors including younger patient age and earlier treatment may play a role. Arguing against the latter is that findings were consistent even when restricting analyses to patients treated within 60 days of symptom onset. Overall, our findings underscore that caution should be used in extrapolating literature on the outcomes from anti-NMDA receptor encephalitis to other forms of AE.

Strengths of this study include the large number of participants, inclusion of various forms of $\mathrm{AE}$, interrogation of depression and sleep along with fatigue, and the recruitment of several cohorts yielding similar principal findings with respect to fatigue impact. Limitations included a likely referral bias toward more challenging cases, such as those with seronegative AE and SREAT associated with long times from symptom onset to diagnosis in many patients, dependence on patients' self-report for fatigue, and broad and variable time frames from symptom onset to study enrollment. Although patients' medical records were not accessible in cohort 1 and thus verification of diagnoses and characterization of many clinical variables were not possible, this limitation was addressed in cohort 2, where we carefully reviewed patients' medical records to verify inclusion and exclusion criteria, diagnosis, demographics, and clinical information.
Fatigue is a prominent feature affecting the quality of life in $\mathrm{AE}$, should be evaluated as part of ongoing medical care, and may be an important outcome in treatment trials. These findings necessitate evaluation in infectious encephalitis and research into the consequences of postencephalitis fatigue, including on activities of daily living and return to education or work. Moreover, an understanding of the biological underpinnings of fatigue after encephalitis is needed to develop targeted treatments.

\section{Acknowledgment}

The authors thank the Aarons family for their generous support of the Johns Hopkins Encephalitis Center.

\section{Study Funding}

The authors report no targeted funding.

\section{Disclosure}

L.A. Diaz-Arias reports no disclosures relevant to the manuscript. A.K. Yeshokumar is now an employee of Bristol Meyers Squibb (but was not at the time that this work was completed). B. Glassberg, J.F. Sumowski, A. Easton, J.C. Probasco, and A. Venkatesan report no disclosures relevant to the manuscript. Go to Neurology.org/NN for full disclosures.

\section{Publication History}

Received by Neurology: Neuroimmunology \& Neuroinflammation March 18, 2021. Accepted in final form June 21, 2021.

\begin{tabular}{lll} 
Appendix & Authors & \\
\hline Name & Location & Contribution \\
\hline $\begin{array}{l}\text { Luisa A. Diaz- } \\
\text { Arias, MD }\end{array}$ & $\begin{array}{l}\text { Johns Hopkins University } \\
\text { School of Medicine, } \\
\text { Baltimore, MD }\end{array}$ & $\begin{array}{l}\text { Study design, data collection, } \\
\text { data analysis, and manuscript } \\
\text { writing }\end{array}$ \\
\hline $\begin{array}{l}\text { Anusha K. } \\
\text { Yeshokumar, } \\
\text { MD }\end{array}$ & $\begin{array}{l}\text { Icahn School of Medicine } \\
\text { at Mount Sinai, New York }\end{array}$ & $\begin{array}{l}\text { Study design, data collection, } \\
\text { data analysis, and manuscript } \\
\text { writing }\end{array}$ \\
\hline $\begin{array}{l}\text { Brittany } \\
\text { Glassberg, } \\
\text { MD }\end{array}$ & $\begin{array}{l}\text { Icahn School of Medicine } \\
\text { at Mount Sinai, New York }\end{array}$ & $\begin{array}{l}\text { Data collection and revising } \\
\text { the manuscript content }\end{array}$ \\
\hline $\begin{array}{l}\text { James F. } \\
\text { Sumowski, } \\
\text { PhD }\end{array}$ & $\begin{array}{l}\text { Icahn School of Medicine } \\
\text { at Mount Sinai, New York }\end{array}$ & $\begin{array}{l}\text { Revising the manuscript } \\
\text { content }\end{array}$ \\
\hline $\begin{array}{l}\text { Ava Easton, } \\
\text { PhD }\end{array}$ & $\begin{array}{l}\text { University of Liverpool, } \\
\text { United Kingdom }\end{array}$ & $\begin{array}{l}\text { Study design and revising the } \\
\text { manuscript content }\end{array}$ \\
\hline $\begin{array}{l}\text { John C. } \\
\text { Probasco, MD }\end{array}$ & $\begin{array}{l}\text { Johns Hopkins University } \\
\text { School of Medicine, } \\
\text { Baltimore, MD }\end{array}$ & $\begin{array}{l}\text { Data collection, data analysis, } \\
\text { and revising the manuscript } \\
\text { content }\end{array}$ \\
\hline $\begin{array}{l}\text { Arun } \\
\text { Venkatesan, } \\
\text { MD, PhD }\end{array}$ & $\begin{array}{l}\text { Johns Hopkins University } \\
\text { School of Medicine, } \\
\text { Baltimore, MD }\end{array}$ & $\begin{array}{l}\text { Study design, data collection, } \\
\text { data analysis, and manuscript } \\
\text { writing }\end{array}$ \\
\hline & &
\end{tabular}

\section{References}

1. Dubey D, Pittock SJ, Kelly CR, et al. Autoimmune encephalitis epidemiology and a comparison to infectious encephalitis. Ann Neurol. 2018;83(1):166-177. doi: 10. 1002/ana.25131.

2. Cohen J, Sotoca J, Gandhi S, et al. Autoimmune encephalitis. Neurology. 2019;92(9): e964-e972. doi: 10.1212/WNL.0000000000006990. 
3. Venkatesan A. Epidemiology and outcomes of acute encephalitis. Curr Opin Neurol. 2015;28(3):277-282. doi: 10.1097/WCO.0000000000000199.

4. Granerod J, Davies NWS, Ramanuj PP, Easton A, Brown DWG, Thomas SL. Increased rates of sequelae post-encephalitis in individuals attending primary care practices in the United Kingdom: a population-based retrospective cohort study. J Neurol. 2017;264(2):407-415. doi: 10.1007/s00415-016-8316-8.

5. Harris L, Griem J, Gummery A, et al. Neuropsychological and psychiatric outcomes in encephalitis: a multi-centre case-control study. PLoS One. 2020;15(3):e0230436. doi: 10.1371/journal.pone.0230436.

6. Yeshokumar AK, Gordon-Lipkin E, Arenivas A, et al. Neurobehavioral outcomes in autoimmune encephalitis. J Neuroimmunol. 2017;312:8-14. doi: 10.1016/j.jneuroim.2017.08.010.

7. de Bruijn MAAM, Aarsen FK, van Oosterhout MP, et al. Long-term neuropsychological outcome following pediatric anti-NMDAR encephalitis. Neurology. 2018;90(22):e1997-e2005. doi: 10.1212/WNL.0000000000005605.

8. Laurent C, Capron J, Quillerou B, et al. Steroid-responsive encephalopathy associated with autoimmune thyroiditis (SREAT): characteristics, treatment and outcome in 251 cases from the literature. Autoimmun Rev. 2016;15(12):1129-1133. doi: 10.1016/ j.autrev.2016.09.008.

9. Mckeon GL, Robinson GA, Ryan AE, et al. Cognitive outcomes following anti-Nmethyl-D-aspartate receptor encephalitis: a systematic review. J Clin Exp Neuropsychol. 2018;40(3):234-252. doi: 10.1080/13803395.2017.1329408.

10. Blum RA, Tomlinson AR, Jetté N, Kwon CS, Easton A, Yeshokumar AK. Assessment of long-term psychosocial outcomes in anti-NMDA receptor encephalitis. Epilepsy Behav. 2020;108:107088. doi: 10.1016/j.yebeh.2020.107088.

11. Tomlinson AR, Blum RA, Jetté N, Kwon CS, Easton A, Yeshokumar AK. Assessment of care transitions and caregiver burden in anti-NMDA receptor encephalitis. Epilepsy Behav. 2020;108:107066. doi: 10.1016/j.yebeh.2020.107066.

12. Ariño H, Muñoz-Lopetegi A, Martinez-Hernandez E, Armangue T, Santamaria J, Dalmau J. Sleep disorders in anti-NMDAR encephalitis (1605). Neurology. 2020; 94(15 suppl):1605. n.neurology.org/content/94/15_Supplement/1605.abstract.

13. Chaudhuri A, Behan PO. Fatigue in neurological disorders. Lancet. 2004;363(9413): 978-988. doi: 10.1016/S0140-6736(04)15794-2.

14. Kluger BM, Krupp LB, Enoka RM. Fatigue and fatigability in neurologic illnesses. Neurology. 2013;80(4):409-416. doi: 10.1212/WNL.0b013e31827f07be.

15. van Sonderen A, Arino H, Petit-Pedrol M, et al. The clinical spectrum of Caspr2 antibody-associated disease. Neurology. 2016;87(5):521-528. doi: 10.1212/WNL. 0000000000002917.

16. Graus F, Titulaer MJ, Balu R, et al. A clinical approach to diagnosis of autoimmune encephalitis. Lancet Neurol. 2016;15(4):391-404. doi: 10.1016/S1474-4422(15)00401-9.

17. Titulaer MJ, McCracken L, Gabilondo I, et al. Late-onset anti-NMDA receptor encephalitis. Neurology. 2013;81(12):1058-1063. doi: 10.1212/WNL.0b013e3182a4a49c.

18. Chung FRCPCF, Yegneswaran MBBSB, Liao MDP, et al. STOP questionnaire: a tool to screen patients for obstructive sleep apnea. Anesthesiol J Am Soc Anesthesiol. 2008; 108(5):812-821. doi: 10.1097/ALN.0b013e31816d83e4.

19. Fisk JD, Ritvo PG, Ross L, Haase DA, Marrie TJ, Schlech WF. Measuring the functional impact of fatigue: initial validation of the fatigue impact scale. Clin Infect Dis. 1994;18(suppl 1):S79-S83. doi: 10.1093/clinids/18.supplement_1.s79.

20. Marrie RA, Miller DM, Chelune GJ, Cohen JA. Validity and reliability of the MSQLI in cognitively impaired patients with multiple sclerosis. Mult Scler. 2003;9(6): 621-626. doi: 10.1191/1352458503ms971oa.

21. Fischer JS, LaRocca NG, Miller DM, Ritvo PG, Andrews H, Paty D. Recent developments in the assessment of quality of life in multiple sclerosis (MS). Mult Scler. 1999;5(4):251-259. doi: 10.1177/135245859900500410.

22. Beck AT, Steer RA, Brown GK. BDI-FastScreen for Medical Patients. Psychological Corporation; 2000.

23. Buysse DJ, Reynolds CF III, Monk TH, Berman SR, Kupfer DJ. The Pittsburgh Sleep Quality Index: a new instrument for psychiatric practice and research. Psychiatry Res. 1989;28(2):193-213. doi: 10.1016/0165-1781(89)90047-4

24. Fisk JD, Pontefract A, Ritvo PG, Archibald CJ, Murray TJ. The impact of fatigue on patients with multiple sclerosis. Can J Neurol Sci. 1994;21(1):9-14.

25. Schiehser DM, Delano-Wood L, Jak AJ, et al. Validation of the Modified Fatigue Impact Scale in mild to moderate traumatic brain injury. J Head Trauma Rehabil. 2015;30(2):116-121. doi: 10.1097/HTR.0000000000000019.

26. Moving ahead. Modified Fatigue Impact Scale (MFIS). 2014. movingahead.psy.unsw. edu.au/documents/research/outcome $\% 20$ measures/adult/TBI\%20Related\% 20Symptoms/Website\%20MFIS.pdf.

27. Kos D, Kerckhofs E, Carrea I, Verza R, Ramos M, Jansa J. Evaluation of the Modified Fatigue Impact Scale in four different European countries. Mult Scler. 2005;11(1): 76-80. doi: 10.1191/1352458505ms1117oa.
28. Beck AT, Steer RA, Carbin MG. Psychometric properties of the Beck Depression Inventory: twenty-five years of evaluation. Clin Psychol Rev. 1988;8(1):77-100. doi: 10.1016/0272-7358(88)90050-5.

29. Spira AP, Beaudreau SA, Stone KL, et al. Reliability and validity of the Pittsburgh Sleep Quality Index and the Epworth Sleepiness Scale in older men.J Gerontol A Biol Sci Med Sci. 2012;67(4):433-439. doi: 10.1093/gerona/glr172.

30. Venkatesan A, Michael BD, Probasco JC, Geocadin RG, Solomon T. Acute encephalitis in immunocompetent adults. Lancet. 2019;393(10172):702-716. doi: 10. 1016/S0140-6736(18)32526-1.

31. Gordon-Lipkin E, Yeshokumar AK, Saylor D, Arenivas A, Probasco JC. Comparative outcomes in children and adults with anti-N-methyl-D-aspartate (anti-NMDA) receptor encephalitis. J Child Neurol. 2017;32(11):930-935. doi: 10.1177/ 0883073817720340 .

32. Attarian HP, Brown KM, Duntley SP, Carter JD, Cross AH. The relationship of sleep disturbances and fatigue in multiple sclerosis. Arch Neurol. 2004;61(4):525-528. doi: 10.1001/archneur.61.4.525.

33. Brenner P, Granqvist M, Königsson J, Al Nimer F, Piehl F, Jokinen J. Depression and fatigue in multiple sclerosis: relation to exposure to violence and cerebrospinal fluid immunomarkers. Psychoneuroendocrinology. 2018;89:53-58. doi: 10.1016/j.psyneuen. 2018.01.002.

34. Binks SNM, Veldsman M, Easton A, et al. Residual fatigue and cognitive deficits in patients after leucine-rich glioma-inactivated 1 antibody encephalitis. JAMA Neurol. 2021;78(5):617-619. doi: 10.1001/jamaneurol.2021.0477.

35. Kotterba $S$, Neusser $T$, Norenberg C, et al. Sleep quality, daytime sleepiness, fatigue, and quality of life in patients with multiple sclerosis treated with interferon beta- $1 \mathrm{~b}$ : results from a prospective observational cohort study. BMC Neurol. 2018;18(1):123. doi: 10.1186/s12883-018-1113-5.

36. Skorvanek M, Gdovinova Z, Rosenberger J, et al. The associations between fatigue, apathy, and depression in Parkinson's disease. Acta Neurol Scand. 2015;131(2):80-87. doi: 10.1111/ane.12282.

37. Powell R, Dolan R, Wessely S. Attributions and self-esteem in depression and chronic fatigue syndromes. J Psychosom Res. 1990;34(6):665-673. doi: 10.1016/00223999(90)90111-g.

38. Beck AT, Steer RA, Brown GK. BDI-FastScreen for Medical Patients, Manual. The Psychological Corporation, A Harcourt Assessment Company; 2000.

39. Manjaly ZM, Harrison NA, Critchley HD, et al. Pathophysiological and cognitive mechanisms of fatigue in multiple sclerosis. J Neurol Neurosurg Psychiatry. 2019;90(6): 642-651. doi: 10.1136/jnnp-2018-320050.

40. Hanken K, Eling P, Hildebrandt $\mathrm{H}$. The representation of inflammatory signals in the brain-a model for subjective fatigue in multiple sclerosis. Front Neurol. 2014;5:264. doi: 10.3389 /fneur.2014.00264.

41. White AT, Lee JN, Light AR, Light KC. Brain activation in multiple sclerosis: a BOLD fMRI study of the effects of fatiguing hand exercise. Mult Scler. 2009;15(5):580-586. doi: $10.1177 / 1352458508100034$.

42. Heine J, Prüss H, Kopp UA, et al. Beyond the limbic system: disruption and functional compensation of large-scale brain networks in patients with anti-LGI1 encephalitis. J Neurol Neurosurg Psychiatry. 2018;89(11):1191-1199. doi: 10.1136/jnnp-2017317780 .

43. Venkatesan A, Jagdish B. Imaging in encephalitis. Semin Neurol. 2019;39(3):312-321. doi: $10.1055 / \mathrm{s}-0039-1687838$.

44. Treadway MT, Cooper JA, Miller AH. Can't or won't? Immunometabolic constraints on dopaminergic drive. Trends Cogn Sci. 2019;23(5):435-448. doi: 10.1016/j.tics. 2019.03.003.

45. Titulaer MJ, Höftberger R, Iizuka T, et al. Overlapping demyelinating syndromes and anti-N-methyl-D-aspartate receptor encephalitis. Ann Neurol. 2014;75(3):411-428. doi: 10.1002 /ana.24117.

46. Leis AA, Grill MF, Goodman BP, et al. Tumor necrosis factor-alpha signaling may contribute to chronic West Nile virus post-infectious proinflammatory state. Front Med. 2020;7:164. doi: 10.3389/fmed.2020.00164.

47. Armangue T, Moris G, Cantarín-Extremera V, et al. Autoimmune post-herpes simplex encephalitis of adults and teenagers. Neurology. 2015;85(20):1736-1743. doi: 10. 1212/WNL.0000000000002125.

48. Titulaer MJ, McCracken L, Gabilondo I, et al. Treatment and prognostic factors for long-term outcome in patients with anti-NMDA receptor encephalitis: an observational cohort study. Lancet Neurol. 2013;12(2):157-165. doi: 10.1016/S14744422(12)70310-1.

49. Peng Y, Dai F, Liu L, et al. Validation of the NEOS score in Chinese patients with antiNMDAR encephalitis. Neurol Neuroimmunol Neuroinflamm. 2020;7(5):e860. doi: 10. 1212/NXI.0000000000000860. 


\section{Neurology \\ Neuroimmunology \& Neuroinflammation}

Fatigue in Survivors of Autoimmune Encephalitis

Luisa A. Diaz-Arias, Anusha Kierty Yeshokumar, Brittany Glassberg, et al.

Neurol Neuroimmunol Neuroinflamm 2021;8;

DOI 10.1212/NXI.0000000000001064

This information is current as of August 13, 2021

\section{Updated Information \& Services}

References

Citations

Subspecialty Collections

Permissions \& Licensing

Reprints including high resolution figures, can be found at: http://nn.neurology.org/content/8/6/e1064.full.html

This article cites 46 articles, 3 of which you can access for free at: http://nn.neurology.org/content/8/6/e1064.full.html\#\#ref-list-1

This article has been cited by 1 HighWire-hosted articles: http://nn.neurology.org/content/8/6/e1064.full.html\#\#otherarticles

This article, along with others on similar topics, appears in the following collection(s):

Autoimmune diseases

http://nn.neurology.org//cgi/collection/autoimmune_diseases Encephalitis

http://nn.neurology.org//cgi/collection/encephalitis

Information about reproducing this article in parts (figures,tables) or in its entirety can be found online at:

http://nn.neurology.org/misc/about.xhtml\#permissions

Information about ordering reprints can be found online:

http://nn.neurology.org/misc/addir.xhtml\#reprintsus

Neurol Neuroimmunol Neuroinflamm is an official journal of the American Academy of Neurology.

Published since April 2014, it is an open-access, online-only, continuous publication journal. Copyright

Copyright $\odot 2021$ The Author(s). Published by Wolters Kluwer Health, Inc. on behalf of the American

Academy of Neurology.. All rights reserved. Online ISSN: 2332-7812.

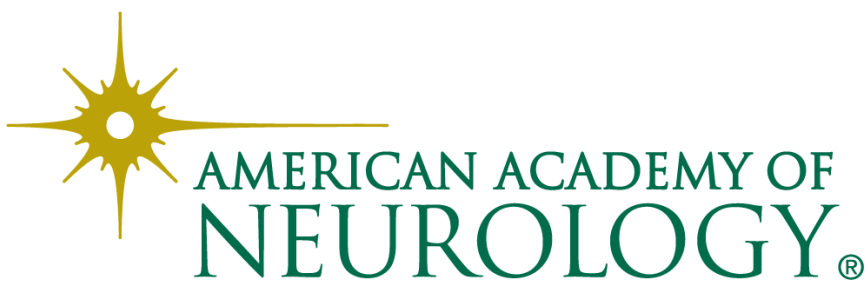

